https://doi.org/10.46344/JBINO.2020.v09i06.38

\title{
AQUEOUS LEAF EXTRACT OF ANNONA MURICATA AMELIORATES CYANIDE-INDUCED TOXICITY IN NEW ZEALAND RABBITS
}

\author{
Omoregie, F.O*. Abu, O.D. and Olude, M.O.
}

Department of Biochemistry, Faculty of Life Sciences, University of Benin, P.M.B 1154, Benin City, Nigeria

Email id : frank.omoregie@uniben.edu

\begin{abstract}
In the present study, aqueous leaf extract of Annona muricata was evaluated for its healing effect on cyanide- induced toxicity in New Zealand Rabbits. Rabbits weighting between 1.2 - $1.8 \mathrm{~kg}$ were used in a 28 -day study. Group A served as the positive control, while groups B and $\mathrm{C}$ were given $400 \mathrm{ppm}$ of cyanide salt $(\mathrm{KCN})$ incorporated in the feed; this was done by dissolving the salt in water and then mixed with the feed in a ratio of 10:1 in addition to daily oral administration of Annona muricata leaf extract $(150 \mathrm{mg} / \mathrm{kg}$ body weight and $300 \mathrm{mg} / \mathrm{kg}$ body weight, respectively). Group D (negative control) was given only $400 \mathrm{ppm}$ of cyanide salt (KCN) supplemented feed. Lipid profile, total thiol concentration in the liver and kidney homogenates and thiocyanate levels in the urine were estimated. The concentration of thiocyanate in the positive and negative control rabbits were significantly increased $(P<$ 0.05) compared to the treatment groups. In the liver and kidney, there was no significant difference $(P>0.05)$ in the concentration of total thiol in the control and treatment groups. However, the concentration was reduced in the negative control (KCN only). These results suggest that aqueous leaf extract of Annona muricata may confer protection against cyanide-induced toxicity.
\end{abstract}

Keywords: Annona muricata, Cyanide, Lipid profile, Total thiol, Thiocyanate, Toxicity 


\section{INTRODUCTION}

Medicinal plants have been used for centuries before the advent of orthodox medicine (Komolafe and Oyelade, 2015). Medicinal plants are important part of natural wealth, serve as important therapeutic agents as well as valuable raw materials for manufacturing numerous traditional and modern medicines (Talalay, 2001). Plants are the richest resources of drugs for traditional system of medicine, modern medicine, nutraceuticals, food supplement, folk medicine, pharmaceutical intermediates and chemical entities for synthetic drug (Hammer et al., 1999). The world Health Organization reported that more than $80 \%$ of the world's population relies on traditional medicine for primary healthcare needs (Ammara et al., 2008).

Cyanide is one of the lethal chemical agents that can be spread as a result of accidental exposure, and by chemical warfare. Chronic cyanide intoxication has been linked to the pathogenesis of goiter (Cliff et al., 1986), tropical ataxic neuropathy (Osuntokun, 1981) and spastic paraparesis (Howlett et al., 1990). The routes of human exposure of cyanide may be either dietary or environment. The mechanism of cyanide toxicity involves the binding of ferric ion in mitochondria cytochrome oxidase preventing electron transport in the cytochrome system and bringing oxidative phosphorylation and ATP production to a halt. The toxicity of cyanide in aerobic organisms arises from inhibition of cytochrome oxidase, the terminal electron acceptor in the respiratory chain, thus cyanide block electron transport, mitochondrial oxygen

utilization and cellular respiration (Jones ef al., 1984; Yen et al., 1995).

Once ingested, cyanide is detoxified by enzymatic conversion to a less toxic renally excreted metabolite thiocyanate. A small amount of cyanide is also detoxified by vitamin $\mathrm{B}_{12}$ precursor, hydroxycobalamin. This chelating agent binds cyanide to form non-toxic cyanocobalamin (Borron and Baud, 1996).

Annona muricata (soursop) is an upright, low-branching tree reaching 8-10 meters (Popenoe et al., 1920). The tree has green, glossy evergreen leaves (Paul et al., 1998). The flowers appear anywhere on the trunk or any branch (Salazar, 1965). It is usually grown from seeds which can be stored for several months before planting. Germination of seeds usually takes three weeks, but under suboptimal conditions can be delayed for up to 2-3 months. Alternatively, propagation of genotypes and for the elimination of viral and disease infection, with the exception of a few cultivars, clonal propagation of the Annona species by rootstocks or cultivars of known agronomic potential could eliminate tree to tree variability in growth and productivity. However, the seedling rootstocks are highly variable in vigor and disease resistance and consequently scion growth and productivity are also variable. They are considered as minor tropical fruits due to strict environmental requirements for tree planting and the short post-harvest life of their fruits (Encina, 2005). Annona muricata is one of the medicinal plants in 
Nigeria used in the management of various diseases.

Here, we investigated the effect of aqueous leaf extract of Annona muricata on $\mathrm{CN}^{-}$induced toxicity in New Zealand rabbits. The liver, kidney, blood and urine sample were used for this work.

\section{MATERIALS AND METHODS}

\section{Animals and feeding}

Four groups of New Zealand White rabbits (four per group) aged about two months were used for this experiment. They were housed in clean disinfected metal hutches and initially acclimatized on growers' mash (Bendel Feed and Flour Mills Ltd., Ewu, Nigeria) for one week. One group received growers mash only, while another group was fed growers mash and 400ppm inorganic cyanide (Potassium cyanide). Members of the third group were fed with $\mathrm{KCN}$ alongside with daily oral dose of aqueous leaf extract of Annona muricata (150mg) and member of the fourth group were also fed with $\mathrm{KCN}$ and $300 \mathrm{mg}$ daily oral dose of aqueous leaf extract of $A$. muricata.

The jelly-like syrup was administered orally once daily to the rabbits through sterile disposable syringes. Prior to presentation, the feeds were mixed with water in the ratio of 10:1 (w/v) to attain an acceptable texture. Each rabbit was fed at the rate of $55 \mathrm{~g}$ feed/day. Clean drinking water was liberally provided while stale feed remnants were daily weighed and discarded prior to fresh feed presentations. All animals were weighed weekly. After three weeks, feeding was terminated.

\section{Body Weight Measurement}

The weights of the experimental animals in each group were determined at the beginning and the end of the experiment and shortly before the animals were sacrificed. The average weight gain and loss were estimated from the values obtained from each group.

\section{Determination of Feed Intake}

The amount of feed consumed per rabbit per day was estimated by determining the difference between weight of feed given and feed leftover.

\section{Plant Sample Collection}

The plant was obtained from a forest area in Benin (Ekehuan) and identified by Dr. Akinnibosun Henry. Voucher specimen was kept in the herbarium with voucher number $U_{B H} 356$ at the Department of Plant Biology and Biotechnology, University of Benin, Benin City.

The leaves of this plant were air-dried in the laboratory at the Department of Biochemistry, University of Benin, Benin City. The leaves were later pulverized to powdery form in Pharmacognosis laboratory at the Faculty of Pharmacy, University of Benin.

\section{Plant Sample Preparation}

Powdered leaves (300g) of Annona muricata was soaked in two litres of distilled water for $12 \mathrm{~h}$ with periodic stirring. After 12h, the mixture was filtered with fine cheese cloth, the residue was discarded and the filtrate was used to soak another $300 \mathrm{~g}$ of powdered leaves of same plant above, allowed to stand for another $12 \mathrm{~h}$ with continuous stirring, thereafter, the mixture was again filtered. The residue was 
discarded and the filtrate was used again to soak another $300 \mathrm{~g}$ of the powdered leaves of Annona muricata and allowed to stand for 12 hours with continuous stirring, then was filtered, the residue obtained was disposed and the filtrate was concentrated with the aid of a rotary evaporator and freeze-dried with a lyophilizer.

\section{Collection of Blood}

Blood samples were drawn from the rabbits' heart into citrate vials using sterile disposable 21-guage syringe during sacrifice. Dissected pieces of liver and kidney were rinsed, homogenized in cold normal saline solution and used immediately for the assay of total thiol. Urine was used for the evaluation of thiocyanate. Collected blood samples were used for the assay of lipid profile.

\section{Biochemical Assays Lipid profile analysis}

Cholesterol concentration was estimated by the method of Tinder, (1969). Triacylglyceride (TAG) concentration was estimated by the method of Tietz (1986), High Density Lipoprotein-Cholesterol (HDL-
C) by the method of Lopes-Virella, et al., (1997) and Low Density LipoproteinCholesterol (LDL-C) by the method of Friedewald et al., (1972)

\section{Thiocyanate test}

Thiocyanate level was assayed by the method of Bowler (1994).

\section{Total thiol analysis}

Total thiol concentration was estimated by the method of Thannhauser et al., (1987).

\section{STATISTICAL ANALYSIS}

The results were expressed as mean \pm SEM. Data were analyzed using SPSS (20:0) for difference between all the groups. Duncan's multiple range test was used to test for significant differences between the means at $\mathrm{P}<0.05$.

\section{RESULTS}

Lipid profile of rabbits with cyanideinduced toxicity

The concentrations of cholesterol and triacylglycerol of the negative control are significantly reduced $(p<0.05)$ compared to the treatment groups.

Table 1: Lipid profile of rabbits with cyanide-induced toxicity treated with aqueous leaf extract of Annona muricata

\begin{tabular}{lccccc}
\hline Groups & $\begin{array}{c}\text { Cholesterol } \\
(\mathrm{mg} / \mathrm{dl})\end{array}$ & $\begin{array}{c}\text { TAG } \\
(\mathrm{mg} / \mathrm{dl})\end{array}$ & $\begin{array}{c}\text { HDL-C } \\
(\mathrm{mg} / \mathrm{dl})\end{array}$ & $\begin{array}{c}\text { VLDL-C } \\
(\mathrm{mg} / \mathrm{dl})\end{array}$ & $\begin{array}{c}\text { LDL-C } \\
(\mathrm{mg} / \mathrm{dl})\end{array}$ \\
\hline $\mathrm{A}(\mathrm{Control})$ & $130.20 \pm 10.02$ & $97.20 \pm 12.18$ & $28.20 \pm 4.67$ & $19.44 \pm 1.82$ & $85.00 \pm 8.24$ \\
B $(150 \mathrm{mg} / \mathrm{kg}$ & $151.00 \pm 7.60^{\mathrm{a}}$ & $84.50 \pm 8.44^{\mathrm{a}}$ & $37.25 \pm 2.01^{\mathrm{a}}$ & $16.90 \pm 1.08^{\mathrm{a}}$ & $109.25 \pm 15.20^{\mathrm{a}}$ \\
b.wt.+ KCN $)$ & & & & \\
C (300 mg/kg & $67.00 \pm 5.93^{\mathrm{ab}} 101.00 \pm 10.81^{\mathrm{a}}$ & $27.33 \pm 2.18^{\mathrm{b}}$ & $20.20 \pm 1.30^{\mathrm{a}}$ & $20.00 \pm 3.46^{\mathrm{b}}$ \\
b.wt.+ KCN) & & & & & \\
D (KCN only) & $74.33 \pm 6.85^{\mathrm{b}}$ & $70.00 \pm 7.55^{\mathrm{b}}$ & $39.00 \pm 3.19^{\mathrm{a}}$ & $14.00 \pm 1.60^{\mathrm{b}}$ & $21.33 \pm 2.84^{\mathrm{b}}$ \\
\hline
\end{tabular}

Data are expressed as mean \pm SEM $(\mathrm{n}=5)$. 
${ }^{\mathrm{b}} p<0.05$ compared to control, B and C groups.

\section{Levels of thiocyanate in the urine of rabbits}

The concentration of thiocyanate in the positive and negative control rabbits were significantly increased ( $p<$ 0.05) compared to the treatment groups (Table 2).

Table 2: Levels of thiocyanate in the urine of rabbits with cyanide-induced toxicity treated with aqueous leaf extract of Annona muricata

Group $\quad \mathrm{SCN}(\mathrm{mmol} / \mathrm{l})$
A (Control)
$211.04 \pm 6.58$
$\mathrm{B}(150 \mathrm{mg} / \mathrm{kg}$ body wt. $+\mathrm{KCN})$
$192.00 \pm 8.09^{\mathrm{a}}$
C $(300 \mathrm{mg} / \mathrm{kg}$ body wt. $+\mathrm{KCN})$
$171.08 \pm 9.30^{\mathrm{a}}$
$\mathrm{D}(\mathrm{KCN}$ Only)
$265.25 \pm 11.70^{\mathrm{b}}$

Data are expressed as mean \pm SEM $(\mathrm{n}=5)$.

${ }^{\mathrm{b}} p<0.05$ compared to control, $\mathrm{B}$ and $\mathrm{C}$ groups.

\section{Concentrations of total thiol in the kidney and liver of rabbits}

There was no significant difference $(p>0.05)$ in the concentration of total thiol in the control and treatment groups. However, the concentration was reduced in the negative control (KCN only), as shown in Table 3.

Table 3: Concentrations of total thiol in the kidney and liver of rabbits with cyanide-induced toxicity treated with aqueous leaf extract of Annona muricata

\begin{tabular}{lll}
\hline Groups & $\begin{array}{c}\text { Liver total thiols } \\
(\mathrm{mol} / \mathrm{dl})\end{array}$ & $\begin{array}{c}\text { Kidney total thiols } \\
(\mathrm{mol} / \mathrm{dl})\end{array}$ \\
\hline A (Control) & $0.57 \pm 0.12^{\mathrm{a}}$ & $0.37 \pm 0.05$ \\
B (150mg/kg body wt.+KCN) & $0.50 \pm 0.07^{\mathrm{a}}$ & $0.28 \pm 0.03^{\mathrm{a}}$ \\
C (300mg/kg body wt. $+\mathrm{KCN})$ & $0.54 \pm 0.03^{\mathrm{a}}$ & $0.33 \pm 0.03^{\mathrm{a}}$ \\
D (KCN Only) & $0.27 \pm 0.09^{\mathrm{b}}$ & $0.15 \pm 0.05^{\mathrm{b}}$ \\
\hline
\end{tabular}

Data are expressed as mean \pm SEM $(\mathrm{n}=5)$.

${ }^{\mathrm{b}} p<0.05$ compared to control, B and C groups.

\section{DISCUSSION}

Medicinal values of plants have assumed important dimensions in the past few decades (Anjali and Sheetal, 2013). Plants are important sources of potential compounds for the development of new therapeutic agents (Sahoo et al., 2009). These non- nutrients plant chemical compounds or phyto-constituents are responsible for protecting the plant against microbial infections or infestations by pests (Doughari, 2012). The diverse groups of 
secondary metabolites produced by plants have antioxidant potential. Antioxidants block the action of free radicals which have been implicated in the pathogenesis of many diseases and in the ageing process (Arvoma, 2003).

Hepatotoxicity and pathological injury have been found to occur in liver. Antihepatotoxic substances are the remedies to reverse this effect. The results from this study show that the plant Annona muricata has moderate ant-hepatotoxic and anti-hyperlipidemic ability.

Generation of free radicals in the body beyond antioxidant capacity leads to oxidative stress which has been implicated in diseases such as cancer, cardiovascular disease, aging and several other chronic diseases because of their ability to induce oxidative damage to biomolecules such as lipid, DNA and protein (Sosa et al., 2013).

Cyanide-induced toxicity has to do with the inhibition of cytochrome c oxidase, a key enzyme in the electron transport chain. The mechanism of toxicity involves the binding of ferric ion in the mitochondrial cytochrome c oxidase, preventing electron transport in the cytochrome system and bringing oxidative phosphorylation to a halt. Cyanide also inhibits superoxide dismutase, catalase, thus triggering oxidative stress by the generation of reactive oxygen species. ROS scavengers known as antioxidants are widely distributed in medicinal plants and they include plants derived bioactive phytochemicals such as flavonoids, tannins, alkaloids, polyphenols etc. They are major contributor to anti-hepatotoxic capability of most medicinal plants (Nwanna and Oboh, 2007).
In this study, aqueous leaf extract of Annona muricata was evaluated for its healing effect on cyanide- induced toxicity in New Zealand Rabbits

In the liver, the total thiol level of group $B$ rabbits was not significantly different ( $p>0.05$ ) from control, although there was slight reduction in the concentration. Those of group $C$ had a value relatively closer to control (group A) indicating the healing effect of the plant leaf extract on hepatotoxicity. The group without the plant extract (D) had a concentration significantly different $(P<0.05)$ from control group and those of groups $B$ and $C$. This probably indicates oxidative stress due to decrease in the concentration of total thiol. In the kidney, similar result was also observed. The level of total thiol in the control group was not significantly different $(P>0.05)$ from those of groups $B$ and $C$ but significantly different $(P<0.05)$ from group $D$. This may suggest that the plant extract has protective effect against KCN renaltoxicity.

The fall in total thiol concentration in group $D$ is indicative for the rise in the concentration of thiocyanate in table 2 . Cyanide readily displaces hydrogen ion from sulphydryl group to form thiocyanate causing a fall in the level of - $\mathrm{SH}$ in the blood. This can be further elucidated by the action of the enzyme Rhodanese (thiosulfate cyanide sulfurtransferase), ubiquitous enzyme presents in man (Mueller et al., 2001). Rhodanese catalyzes the cyanide-dependent cleavage of thiosulfate to form thiocyanate and sulfite. In spite of extensive studies, the true biological role of this enzyme is still an enigma. It is believed that rhodanese is 2020 November Edition | www.jbino.com | Innovative Association 
involved in cyanide detoxification (Nandi et al., 2004).

The concentration of thiocyanate in group $D$ was significantly different $(P<0.05)$ from control and those administered $150 \mathrm{mg} / \mathrm{kg}$ body weight and $300 \mathrm{mg} / \mathrm{kg}$ body weight Annona muricata leaf extract. Thiocyanate concentration in groups B and $C$ was not significantly different from control group. There was an increase in the concentration of thiocyanate in the urine of rabbits in group $D$ when compared to control group, groups B and C. This agrees with the report of Okolie and Asonye, (2004). They noted that cyanide-fed rabbits had significant higher thiocyanate concentration when compared to rabbits in the control group $(\mathrm{P}<0.5)$. Also, work done by Ralph, (1940), indicated that the administration of cyanide resulted in a greater increase in thiocyanate concentration in serum of rabbits than in dogs. The recovery of cyanide as urinary thiocyanate was rapid in rabbits when compared to dogs (Ralph et al.,1940).

Administration of $150 \mathrm{mg} / \mathrm{kg}$ body weight resulted in an increase in serum total cholesterol, high density lipoproteins cholesterol (HDL-C) and low-density lipoproteins cholesterol (LDL-C) but decrease in Triacylglycerol (TAG). Invariably, treatment with $300 \mathrm{mg} / \mathrm{kg}$ body weight of Annona muricata leaf extract resulted in a decrease in serum total cholesterol, HDL-C and LDL-C but an increase in TAG. Previous work done (Adeyemi et al, 2008) on rat showed significant decrease $(P<0.5)$ in total cholesterol, HDL-C and LDL-C respectively. Annona muricata leaf extract had anti- hyperlipidemic effect and may reduce lipid peroxidation. (Adeyemi et al, 2008).

Phytochemical screening (Qualitative) of Annona muricata leaves showed the presence of flavonoid, saponins, tannins and alkaloids (Usunobun and Okolie, 2015). All these active ingredients may contribute to the ameliorating properties of the plant extract. Further study on this extract may involve subjecting it to gas chromatography-mass spectrometry (GCMS) to identify biologically active compounds that could be responsible for the observed effect.

\section{CONCLUSION}

The result of this preliminary study suggests the plant leaf extract may have antihyperlipidemic effect and protective potential on the liver and kidney in cyanide induced toxicity in rabbits. Notably, $300 \mathrm{mg} / \mathrm{kg}$ body weight of the plant leaf extract showed more ameliorative effect than $150 \mathrm{mg} / \mathrm{kg}$ body weight.

\section{ACKNOWLEDGEMENT}

The authors wish to acknowledge the following laboratory technologies for their support during the course of this work: Mrs H.O., Obayuwana and Mr K. Akpeh.

\section{REFERENCES}

Adeyemi, D.O., Komolafe, O.A., Adewole, S.O., Obuotor, E.M. (2008). Anti Hyperlipidemic Activities Of Annona muricata (Linn). The Internet Journal of Alternative Medicine. $7: 1$. 
Ammara, H., Salma, R., Farah, D. and Shahid, M. (2008). Antimicrobial activity of some plant extracts having hepatoprotective effects. Journal of Medicinal Plants Research 3(1):20-23.

Anjali, S. and Sheetal, S. (2013). Phytochemical Analysis and Free Radical Scavenging Potential of Herbal and Medicinal Plant Extracts, Journal of Pharmacognosy and Phytochemistry, 2 (4): 22-29.

Aruoma, O.I. (2003). Methodological consideration for characterizing potential antioxidant action of bioactive components in plant foods. Mutation Research; 523 (524):9-20.

Borron, S.W. and Baud, F.J. (1996). Acute cyanide poisoning: clinical spectrum, diagnosis and treatment. Arch. Toxicol. Indust. Hyg. 47: 307-322.

Bowler, R.G. (1994). The determination of thiocyanate in blood serum. Clinical laboratory and medical unit, London hospital.38:385-388.

Cliff, J., Lundquist, P., Rosling, H, Sorbo, B. and Wide, L. (1986). Thyroid function in a cassava - eating population affected by epidemic spastic paraparesis. Acta Endocrinol.. 113: 523-528.

Doughari, J.H. (2012). Phytochemicals: extraction methods, basic structures and mode of action as potential chemotherapeutic agents. Venketeshwer Rao Phytochemicals-A global perspective of their role in nutrition and health: In tech. pp.2-14.

Encina, C.L. (2005). Annona spp. Atemoya, cherimoya, soursop and sugar apple. In: $R$ E, Litz (Ed.), Biotechnology of Fruits and Nut Crops: In Biotechnology in Agriculture Series. No, 29, chapter 3.1, pp. 74-87.

Friedewald, W.T., Levy, R.I. and Fredrickson, D.S. (1972). Estimation of the concentration of low-density lipoprotein cholesterol in plasma, without use of the preparative ultracentrifuge. Clin. Chem. 18:499-502.

Hammer, K.A., Carson, C.F. and Riley, T.V. (1999). Journal of Applied Microbiology 86: 985-990.

Howlett, W.P., Brubakkar, G.R., Mlingi, N. and Rosling, H. K. (1990). An epidemic upper motor disease studies in Tanzania. Brain, 113: 223-236.

Jones, M.G., Bickar, D., Wilson, M.T., Brunori, M., Colosimo, A. and Sarti, P.A. (1984). Reexamination of the reactions of cyanide with cytochrome oxidase. Biochem. J. 220: 5-9.

Komolafe, K. and Oyelade, W.A. (2015). Phytochemical screening and invitro antioxidant activity of parkia biglobosa extract. Journal of Biology, Agriculture and Healthcare. 5(9)91-95.

Lopes-Virella, M. F., Stone, P., Ellis, S. and Cowell, J.A. (1997). Cholesterol determination in high-density lipoproteins separated by three different methods. Clin. Chem. 28:882-884. 
Mueller, E.G., Palenchar, P.M. and Buck, C.J. (2001). The role of the cysteine residue of thil in the generation of 4-thiouridine in tRNA. J Biol. Chem. 276; 33588-33595.

Nandi, D.I., Horowitz, P.M. and Wesley, J. (2004). Rhodanese as thioredoxin oxidase. Int .J. Biochem. cell Biol.32:465-473.

Nwanna, E.E. and Oboh, G. (2007). Antioxidants and Hepatoprotective properties of polyphenol extract from Telfaracia occidentalis Leaves. Pak. J. Biol. Sci., 10 (16):2682-2687.

Osuntokun, B.O. (1981). Cassava diet, chronic cyanide intoxication and neuropathy in Nigerian Africans. World Rev Nutr Diet, 36:141-173.

Paul, R.E. (1998). Soursop. In P.E., Shaw and H T,Chan, (Eds.), Tropical and Subtropical Fruits, pp386-400.

Popenoe, W. (1920). Manual of Tropical and Subtropical Fruits. The Macmillan Co. New York, pp182-186.

Ralph, G., Smith, B.M. and John, H. (1940). Thiocyanate formation in cyanide poisoning as affected by methylene blue and sodium nitrite. Journal of pharmacology and experimental therapeutics. 68(3):351-364.

Sahoo, N., Choudhury, K. and Manchikanti, P. (2009). Manufacturing of biodrugs: Need for harmonization in regulatory standards. BioDrugs. 23(4):21729.
Salazar, C.G. (1965).Some tropical fruits of minor economic importance in Puerto Rico. Review Agriculture Puerto Rico, 52:135-156

Sosa, V., Moline, T., Somoza, R., Paiucci, R., Kondoh, H.L., and Leonart, M.E. (2013). Oxidative Stress and Cancer: An overview, Ageing Research. Review. 12:376-390.

Talalay, P. (2001).The importance of using scientific principles in the development of medicinal agents from plants. Academic medicine 76(3):238-247.

Thannhauser, T. W., Konishi, Y, and Scheraga, H A. (1987). Analysis for disulfide bonds in peptides and proteins. Methods Enzymol.143:115-119.

Tietz, N.W. (1986) Textbook of Clinical Chemistry, W.B. Saunders, pp.888.

Tinder, P. (1969). Determination of glucose in the blood using glucose oxidase with alternative oxygen acceptor. Ann. Clin. Biochem. 6:24-25.

Usunobun, U. and Okolie, N.P. (2015). Phytochemical Analysis and Mineral Composition of Annona muricata leaves. IJRCD . 1 (1):38-42.

Yen, D., Tsai, J., Wang, L., Kao, W., Hu, S., Lee, C. and Deng, J. (1995). The clinical experience of acute $\mathrm{CN}$ - poisoning. Amer. J. Emerg. 13:524-528. 